Marie-Thérèse Berthier · Alain Houde

Jean Bergeron · Denis Prud' homme

Jean-Pierre Després · Marie-Claude Vohl

\title{
Effect of the factor VII R353Q missense mutation on plasma apolipoprotein B levels: impact of visceral obesity
}

Received: 10 March 2003/ Accepted: 30 April 2003/Published online: 8 July 2003

(C) The Japan Society of Human Genetics and Springer-Verlag 2003

\begin{abstract}
An atherogenic dyslipidemia, characterized by increased plasma triglyceride and apolipoprotein (apo) B levels, low HDL-cholesterol concentrations and the development of small, dense LDL particles has been associated with the presence of abdominal-visceral obesity. Visceral obesity is also associated with a hypercoagulate state and elevated concentrations of procoagulant factors such as factor VII. Moreover, it is known that some genetic variants in the gene encoding factor VII alter its activity and concentration, and consequently these variants may have an impact on atherosclerosis development. The objective of this study was to verify whether the factor VII R353Q polymorphism contributes to predict the risk of an atherogenic dyslipidemia in absence and in the presence of visceral obesity. A sample of 299 French-Canadian men, selected in order to cover a wide range of body fatness values, participated in this study. We observed that the R353 allele was more commonly observed among men characterized by apo B levels below $1.09 \mathrm{~g} / 1$ than among men with apo B levels greater or above this threshold value (allele frequency of 92.1 vs $85.4 \%, \chi^{2}=6.18$, $P=0.01)$. Multivariate analyses further showed that the genotype R353/R353 was associated with a lower risk to exhibit atherogenic concentrations of total-apo B
\end{abstract}

M.-T. Berthier $\cdot$ A. Houde $\cdot$ J. Bergeron

J.-P. Després · M.-C. Vohl $(\square)$

Lipid Research Center, CHUQ Pavilion CHUL,

2705 Laurier Blvd, TR93, Sainte-Foy, Québec, G1V 4G2, Canada

E-mail: marie-claude.vohl@crchul.ulaval.ca

Tel.: + 1-418-6564141 ext. 8280

Fax: + 1-418-6542145

M.-T. Berthier · J.-P. Després · M.-C. Vohl

Food Sciences and Nutrition Department,

Laval University, Québec, Canada

D. Prud homme

Human Kinetics, Faculty of Health Sciences,

University of Ottawa, Ontario, Canada

J.-P. Després

Quebec Heart Institute, Sainte-Foy, Québec, Canada $(\geq 1.09 \mathrm{~g} / \mathrm{l})$ and LDL apo B $(\geq 0.95 \mathrm{~g} / \mathrm{l})$ before (odds ratio: $0.47,95 \% \mathrm{CI}=0.27-0.90, P=0.02$; odds ratio: $0.46,95 \% \mathrm{CI}=0.25-0.85, P=0.01$, respectively) and after adjustments for age and visceral AT (odds ratio: $0.49,95 \% \mathrm{CI}=0.24-0.91, P=0.02$; odds ratio: 0.44 , $95 \% \mathrm{CI}=0.23-0.85, P=0.01$, respectively). When the two genotype groups were further divided on the basis of visceral adipose tissue (AT) accumulation using a cutoff point of $130 \mathrm{~cm}^{2}$, we observed that R353/R353 homozygotes with low visceral AT were characterized by a more favorable lipoprotein-lipid profile, mainly lower total-cholesterol, total-apo B, and LDL-apo B levels compared with R353/R353 homozygotes with high levels of visceral AT. In contrast, irrespective of obesity, plasma lipid levels among carriers of the Q353 allele were similar to those of viscerally obese men homozygous for the R353 allele. In conclusion, results of the present study suggest that the factor VII R353 allele is associated with lower concentrations of plasma apo B levels. However, the presence of visceral obesity abolishes this effect. Further studies will be necessary to confirm this association and the mechanism involved.

Keywords Factor VII - Missense mutation · Atherogenic dyslipidemia $\cdot$ Visceral obesity

\section{Introduction}

An atherogenic dyslipidemia, characterized by increased plasma triglyceride and apolipoprotein (apo) B levels, low HDL-cholesterol concentrations and the development of small, dense LDL particles has been associated with the presence of abdominal-visceral obesity (Després et al. 1989; Pouliot et al. 1992; Després 1994; Lamarche et al. 1999). Visceral obesity is also associated with insulin resistance, a hypercoagulate state as well as with elevated concentrations of procoagulant factors such as fibrinogen, factor VII, Von Willebrand factor and plasminogen activator inhibitor-1 (Avellone et al. 1994; 
Bavenholm et al. 1995; Vambergue et al. 2001). This constellation of metabolic alterations is believed to play an important role in the increased risk of coronary heart disease (CHD) associated with visceral obesity (Peiris et al. 1989; Després 1992; Després et al. 1990, 1996).

Because thrombosis is an essential contributor to the risk of an acute coronary event (Fuster et al. 1992), alterations of plasma coagulation factors activity have been associated with a higher risk of ischemic heart disease (Vaisanen et al. 1995). The coagulation cascade consists of series of reactions where several coagulation factors are successively activated. Factor VII, a vitamin$\mathrm{K}$-dependent glycoprotein, plays a key role in the pathway, and its activation depends on mediators such as factors XIIa, Xa, IXa, calcium ions, phospholipids and tissue factor (TF) (Rao and Rapaport, 1988). With its obligatory cofactor, TF, the factor VII is the major trigger for the coagulation cascade. Increased factor VII clotting activity has been observed in plasma of individuals with increased risk of fatal CHD (Heinrich et al. 1994; Kjalke et al. 2000; Miller et al. 1996). The Northwick Park Heart Study (NPHS) has also shown that raised plasma factor VII coagulant activity is associated with an increased risk of ischemic heart diseases, particularly for events occurring within five years (Meade et al. 1986). It is known that some genetic variants in the gene encoding factor VII alter its activity and concentration. Consequently, these variants may have an impact on atherosclerosis development. The factor VII R353Q polymorphism is caused by the substitution of a guanine to an adenine in exon 8, at position 10976 of the gene (Green et al. 1991). Green and co-workers have suggested that the polymorphism R353Q affects the catalytic properties of the factor VII and/or the intracellular and extracellular processing of the molecule (Green et al. 1991). Several studies have also reported a strong association between a common missense mutation of the factor VII (R353Q) and factor VII levels (Green et al. 1991; Lane et al. 1992; Saha et al. 1994; Pankow et al. 1998; de Maat et al. 1997; Hunault et al. 1997). The presence of factor VII R353Q variant is likely to reduce an individual risk of thrombosis and myocardial infarction without producing bleeding problem (Green et al. 1991).

The objective of this study was to verify, first, whether this polymorphism is associated with an atherogenic dyslipidemic state and then, whether the presence of visceral obesity could modulate this possible association.

\section{Subjects and methods}

\section{Subjects}

A total of 299 men recruited from the greater Quebec City area and selected in order to cover a wide range of body fatness values participated to this study. These men were all non-smokers and free of metabolic disorders such as hypertension, type-II diabetes and coronary heart disease. None of them was using medication known to affect insulin action, coagulation or plasma lipoprotein levels.
Since these men were recruited in order to cover body fatness values, with the objective of studying obesity-related metabolic complications, slight alterations of the lipoprotein/lipid profile as well as the pro-thrombotic/pro-inflammatory profile may be observed. However, none of them had severe dyslipidemia, such as hypercholesterolemia or type-III dysbetalipoproteinemia. Solicitation was made through the media. This study received the approval of the Ethic committee of Laval University.

\section{Anthropometric measurements}

Waist and hip circumferences, body weight and height were measured following standardized procedure (Van der kooy and Seidell 1993). Visceral adipose tissue (AT) area was measured by computed tomography on a Siemens Somatom DRH scanner (Erlagen, Germany), as previously described (Després et al. 1991; Ferland et al. 1989).

\section{Lipoprotein, lipid measurements}

Blood cholesterol and triglyceride concentrations were enzymatically measured on a Technicon RA-500 analyser (Bayer Corporation, Tarrytown, N.Y.). VLDL was isolated by ultracentrifugation $(\mathrm{d}<1.006 \mathrm{~g} / \mathrm{ml})$ and the HDL fraction was obtained after precipitation of LDL in the infranatant $(\mathrm{d}>1.006 \mathrm{~g} / \mathrm{ml})$ with heparin and $\mathrm{MnCl}_{2}$ (Moorjani et al. 1987). Apo B concentrations were measured in plasma and infranatant (LDL-apo B; $\mathrm{d}>1.006 \mathrm{~g} / \mathrm{ml}$ ) by the rocket immunoelectrophoretic method of Laurell (1966), as previously described (Moorjani et al. 1987). Serum standards were prepared in our laboratory, calibrated against reference sera obtained from the Center for Disease Control (Atlanta, Ga.) which had been lyophilized, and stored at $-85{ }^{\circ} \mathrm{C}$ until use.

\section{Glucose and insulin measurements}

Plasma glucose was enzymatically measured (Richterich and Dauwalder 1971) and plasma insulin levels were assessed by radioimmunoassay with polyethylene glycol separation (Desbuquois and Aurbach 1971).

\section{Genotype determination}

The factor VII R353Q genotyping has been done using the method previously published by Saha et al. (1994).

\section{Statistical analysis}

In order to reduce the skewness of their distribution, triglyceride, VLDL-apo B, HDL-cholesterol, VLDL-cholesterol, fasting glucose and insulin levels were $\log _{10}$-transformed prior to analysis. Student's $t$-test was used to perform comparisons between the two genotype groups. The gene-counting method with a $\chi^{2}$-test was used to compare the frequency of the different alleles between different groups. Multivariate estimation of the risk to exhibit some metabolic disorders of dyslipidemia was studied before and after adjustments for age and for age and visceral AT. The Pearson correlation product coefficient was used to quantify relationships between variables within each genotype group before and after adjustment for age. Then, to study how the obesity could modify the effect of genotype on the lipoprotein/lipid profile, subjects were further classified on the basis of visceral AT area. A value of $130 \mathrm{~cm}^{2}$ of cross-sectional visceral AT area was used to identify subjects with elevated versus low visceral AT accumulation as it was previously reported that men with visceral AT accumulation 
greater than this value were frequently characterized by a cluster of metabolic abnormalities increasing the risk of cardiovascular disease (Després and Lamarche 1993). Comparisons among subgroups were performed using an ANOVA analysis in order to quantify the effect of the genotype itself and the effect of visceral AT. The Duncan multiple-range comparison test was used in cases where a significant group effect was noted. Analysis of covariance was also used to adjust variables for age and the differences between the groups were known with the LSMEANS procedure. These statistical analyses were performed with the SAS statistical package (SAS, Cary, N.C.).

\section{Results}

In the sample of 299 French-Canadian men studied, the relative frequency of the Q353 allele was of 0.11 and in agreement with the Hardy-Weinberg equilibrium. As shown in Table 1 and Table 2, the two genotype groups were similar for age, weight, BMI, waist circumference, the amount of visceral AT, fasting plasma glucose and insulin levels, as well as for plasma lipoprotein/lipid values. A trend toward higher plasma total-cholesterol levels was observed in carriers of the Q353 allele after adjustment for age and visceral AT $(P=0.06)$.

In order to verify the association of the R353Q variant with different parameters of the atherogenic dyslipidemia, allele frequencies of the R353Q variant was compared between groups divided on the basis of totalapo B using a cutoff point of $1.09 \mathrm{~g} / 1$, which represents the value used to classify subjects at risk to develop a coronary artery event (Connelly et al. 1999). The frequency of the R353 allele was of $92.1 \%$ in the group with apo B concentrations below $1.09 \mathrm{~g} / 1$ and of $85.4 \%$ in the group characterized by apo B concentrations equal or higher than $1.09 \mathrm{~g} / 1\left(\chi^{2}=6.18, P=0.01\right)$. According to these first results, multivariate models were used to estimate the contribution of the genotype in the prediction of the risk to exhibit increased total-apo B concentrations (Table 3). We observed that the R353/ R353 genotype is associated with a lower probability to exhibit atherogenic concentrations of total-apo B (totalapo $\mathrm{B} \geq 1.09 \mathrm{~g} / 1$ ) or higher LDL-apo $\mathrm{B}$ levels (LDLapo $\mathrm{B} \geq 0.95 \mathrm{~g} / \mathrm{l}$ ) before (model 1) and after adjustments for age (model 2) or age and visceral AT (model 3). On the other hand, when the same analysis were performed only with subjects with visceral AT higher or equal than $130 \mathrm{~cm}^{2}$ the protective effect of the R353/R353 genotype was lost (model 4, Table 3).

To verify whether the factor VII R353Q missense mutation alters the relationship between the amount of visceral AT and plasma lipoprotein lipid concentrations, Pearson correlation coefficients were computed within each genotype group. The most important correlations are summarized in Table 4 . The amount of visceral AT was positively associated with total-cholesterol, VLDLcholesterol, LDL-cholesterol and total-cholesterol/ HDL-cholesterol ratio, as well as with total-, VLDLand LDL-apo B levels and negatively correlated with HDL-cholesterol concentrations only in R353/R353

Table 1 Subjects' characteristics according to factor VII R353Q genotype. Results are expressed as mean \pm SD, number of subjects is shown in parentheses

\begin{tabular}{|c|c|c|c|c|}
\hline & R353/R353 homozygotes & Q353 carriers $^{\mathrm{a}}$ & $P$ & $P^{\mathrm{b}}$ \\
\hline Age, years & $42.24 \pm 7.94$ (219) & $43.07 \pm 7.79$ & 0.50 & \\
\hline Weight, kg & $88.63 \pm 13.29(218)$ & $89.99 \pm 13.84(55)$ & 0.51 & \\
\hline $\mathrm{BMI}, \mathrm{kg} / \mathrm{m}^{2}$ & $29.31 \pm 4.06(218)$ & $29.69 \pm 4.37(55)$ & 0.56 & \\
\hline Waist circumference, $\mathrm{cm}$ & $100.63 \pm 10.82(219)$ & $102.96 \pm 11.67(54)$ & 0.43 & \\
\hline Visceral adipose tissue area, $\mathrm{cm}^{2}$ & $159.84 \pm 55.38(215)$ & $160.80 \pm 58.11(54)$ & 0.91 & \\
\hline Fasting insulin ${ }^{\mathrm{c}}, \mathrm{pmol} / 1$ & $94.43 \pm 53.91(217)$ & $103.14 \pm 59.99(55)$ & 0.22 & 0.11 \\
\hline Fasting glucose $\mathrm{c}^{\mathrm{c}}, \mathrm{mmol} / 1$ & $5.48 \pm 0.53(218)$ & $5.43 \pm 0.43(55)$ & 0.45 & 0.98 \\
\hline
\end{tabular}

${ }^{\mathrm{a}} \mathrm{Q} 353$ carriers group together: seven Q353/Q353 homozygotes and 50 Q353/R353 heterozygotes

${ }^{\mathrm{b}} P$-value adjusted for age and visceral AT accumulation

${ }^{c} \log _{10}$-transformed prior to statistical analysis

Table 2 Lipoprotein-lipid profile according to the factor VII R353Q genotype. Results are expressed as mean \pm SD, number of subjects is shown in parentheses

\begin{tabular}{|c|c|c|c|c|}
\hline & R353/R353 homozygotes & Q353 carriers $^{\mathrm{a}}$ & $P$ & $P^{\mathrm{b}}$ \\
\hline Total-cholesterol, mmol/1 & $5.13 \pm 0.73(214)$ & $5.33 \pm 0.85(55)$ & 0.10 & 0.06 \\
\hline VLDL-cholesterol $^{\mathrm{c}}, \mathrm{mmol} / \mathrm{l}$ & $0.77 \pm 0.44(203)$ & $0.86 \pm 0.44(54)$ & 0.17 & 0.17 \\
\hline LDL-cholesterol, $\mathrm{mmol} / 1$ & $3.39 \pm 0.73(214)$ & $3.54 \pm 0.76(55)$ & 0.19 & 0.19 \\
\hline HDL-cholesterol $^{\mathrm{c}}, \mathrm{mmol} / 1$ & $0.93 \pm 0.20(214)$ & $0.94 \pm 0.20(55)$ & 0.85 & 0.71 \\
\hline Triglycerides ${ }^{\mathrm{c}}, \mathrm{mmol} / \mathrm{l}$ & $2.08 \pm 1.09(214)$ & $2.25 \pm 0.97(55)$ & 0.17 & 0.14 \\
\hline Total-apo B, g/l & $1.07 \pm 0.21(203)$ & $1.11 \pm 0.25(54)$ & 0.14 & 0.15 \\
\hline VLDL-apo B, g/1 & $0.12 \pm 0.08(129)$ & $0.13 \pm 0.08(33)$ & 0.45 & 0.55 \\
\hline LDL-apo B, g/1 & $0.93 \pm 0.18$ & $0.99 \pm 0.20(54)$ & 0.18 & 0.19 \\
\hline
\end{tabular}

${ }^{\mathrm{a}} \mathrm{Q} 353$ carriers group together: 7 Q353/Q353 homozygotes and 50 Q353/R353 heterozygotes

${ }^{\mathrm{b}} P$-value adjusted for age and visceral AT accumulation

${ }^{\mathrm{c}} \mathrm{Log}_{10}$-transformed prior to statistical analysis 
homozygotes (Table 4). After adjustment for age, associations between the amount of visceral AT and plasma VLDL-apo B or HDL-cholesterol levels were lost in R353/R353 homozygotes. After adjustment for age, in carriers of the Q353 allele, the amount of visceral AT was not associated with any lipoprotein/lipid parameters. These results suggest that the relationship between abdominal obesity and plasma lipoprotein/lipid levels is influenced by the factor VII R353Q polymorphism.

Thus, because visceral obesity seems to modulate the association between the R353Q polymorphism and some

Table 3 Multivariate estimation of the risk to exhibit some metabolic disorders of dyslipidemic state in presence of factor VII R353/ R353 genotype. The common value used to classify subjects at risk to develop a coronary artery event was chosen for total apo B and cholesterol concentrations $(1.09 \mathrm{~g} / 1$ and $5 \mathrm{mmol} / \mathrm{l}$, respectively) (Connelly et al. 1999). Regarding LDL-apo B concentrations, the cutoff point was the median value of $0.95 \mathrm{~g} / 1$. Model 1 no adjustment, Model 2 adjustment for age, Model 3 adjustment for age and visceral AT, Model 4 only subjects with visceral AT equal or higher than $130 \mathrm{~cm}^{2}$, adjustment for age

\begin{tabular}{lcll}
\hline & Odds ratio & $\begin{array}{l}95 \% \text { confidence } \\
\text { intervals }\end{array}$ & $P$ value \\
\hline Total apo B $\geq 1.09 \mathrm{~g} / 1$ & & \\
Model 1 & 0.49 & $0.27-0.90$ & 0.02 \\
Model 2 & 0.51 & $0.27-0.95$ & 0.03 \\
Model 3 & 0.47 & $0.24-0.91$ & 0.02 \\
Model 4 & 0.49 & $0.22-1.11$ & 0.09 \\
LDL apo B $\geq 0.95 \mathrm{~g} / 1$ & & \\
Model 1 & 0.46 & $0.25-0.85$ & 0.01 \\
Model 2 & 0.48 & $0.25-0.90$ & 0.02 \\
Model 3 & 0.44 & $0.23-0.85$ & 0.01 \\
Model 4 & 0.63 & $0.29-1.38$ & 0.25 \\
Cholesterol $\geq 5$ mmol/1 & & \\
Model 1 & 0.56 & $0.30-1.05$ & 0.07 \\
Model 2 & 0.59 & $0.31-1.11$ & 0.11 \\
Model 3 & 0.57 & $0.30-1.10$ & 0.09 \\
Model 4 & 0.81 & $0.37-1.77$ & 0.60 \\
\hline
\end{tabular}

dyslipidemic variables, each genotype group was divided into two subgroups according to visceral AT using a cutoff point of $130 \mathrm{~cm}^{2}$ (Fig. 1). After such stratification and adjustment for age, R353/R353 homozygotes with low visceral AT were characterized by lower total-apo B and LDL-apo B concentrations than their counterparts with visceral obesity. The amount of visceral AT did not significantly influence plasma apo B concentrations in carriers of the Q353 allele (Fig. 1A, B). Similar results were obtained with total-cholesterol levels and the totalcholesterol/HDL-cholesterol ratio (Fig. 1C, D).

\section{Discussion}

The frequency of factor VII R353Q missense mutation among French-Canadians (0.11) was comparable to the frequency reported in other Caucasian populations from the United Kingdom (Green et al. 1991) and Poland (Hunault et al. 1997), but lower than the frequency observed among Dravidian Indians (Saha et al. 1994).

Most studies were interested in the association between factor VII concentrations and/or activity and the R353Q polymorphism of factor VII, but few have examined the effect of this polymorphism on metabolic profile. In addition none of theses studies tested whether the presence of an atherogenic environmental factor such as visceral obesity may modulate the effect of R353Q polymorphism on dyslipidemic risk. We observed that the R353/R353 genotype is associated with a lower risk to exhibit plasma apo B and LDL-apo B levels above atherogenic threshold $(\geq 1.09 \mathrm{~g} / 1$ of totalapo B concentrations). Vergnani and co-workers found an association between the activity of factor VII and apo B levels in a sample of Italian octononagenarians (Vergnani et al. 1998). Apo B contained in lipoproteins is involved in the inhibition of factor VII either directly (de Sousa et al. 1988; Vaisanen et al. 1995) or through intermediate molecules like $\mathrm{TF}$, which activates the

Table 4 Relationships between visceral adipose tissue and lipoprotein-lipid levels according to the factor VII R353Q genotype ( $n$ number of subjects; $r_{1}$ Pearson coefficient before adjustment for age; $r_{2}$ Pearson coefficient after adjustment for age)

\begin{tabular}{|c|c|c|c|c|c|c|}
\hline & \multicolumn{6}{|c|}{ Visceral adipose tissue } \\
\hline & \multicolumn{3}{|c|}{ R353/R353 homozygotes } & \multicolumn{3}{|c|}{ Q353 carriers $^{\mathrm{a}}$} \\
\hline & $n$ & $r_{1}$ & $r_{2}$ & $n$ & $r_{1}$ & $r_{2}$ \\
\hline Total-cholesterol & 210 & $0.27 * * *$ & $0.31 * * *$ & 54 & 0.09 & 0.04 \\
\hline VLDL-cholesterol $^{\mathrm{b}}$ & 200 & $0.39 * * *$ & $0.25 * *$ & 53 & $0.43 * *$ & 0.25 \\
\hline LDL-cholesterol & 210 & $0.15^{* *}$ & $0.26 * *$ & 54 & -0.03 & -0.05 \\
\hline HDL-cholesterol $^{\mathrm{b}}$ & 210 & $-0.32 * * *$ & -0.17 & 54 & $-0.35^{* *}$ & 0.25 \\
\hline Total-apo B & 200 & $0.35^{* * *}$ & $0.33^{* * *}$ & 53 & $0.28 *$ & 0.17 \\
\hline VLDL-apo $\mathrm{B}^{\mathrm{b}}$ & 126 & $0.22 * *$ & 0.12 & 32 & 0.21 & 0.12 \\
\hline LDL-apo B & 200 & $0.30 * * *$ & $0.36^{* * *}$ & 53 & 0.22 & 0.15 \\
\hline Ratio $^{c^{2}}$ & 210 & $0.37 * * *$ & $0.28 * * *$ & 54 & $0.34 *$ & 0.18 \\
\hline
\end{tabular}

$* P<0.05, * * P \leq 0.01, * * * P \leq 0.001$

${ }^{\mathrm{a} Q 353}$ carriers group together: seven Q353/Q353 homozygotes and 50 Q353/R353 heterozygotes

${ }^{\mathrm{b}} \log _{10}$-transformed prior statistical analyses

${ }^{\mathrm{c}}$ Cholesterol/HDL-cholesterol ratio 
Fig. 1A-D Modulation of genotypic effect on apo B and cholesterol concentrations by the presence of visceral obesity. Bars graphs comparing the total-apo B (A), LDL-apo B (B), cholesterol levels (C) and cholesterol/HDL-cholesterol ratio (D), within each $\mathrm{R} 353 \mathrm{Q}$ factor VII genotype in men with low $\left(<130 \mathrm{~cm}^{2}\right)$ or high $\left(\geq 130 \mathrm{~cm}^{2}\right)$ visceral adipose tissue (AT) after adjustment for age. The number below each bar identifies the subgroups: 1 R353/R353 homozygotes and visceral AT $<130 \mathrm{~cm}^{2}(n=71)$, 2 R353/R353 homozygotes and visceral $\mathrm{AT} \geq 130 \mathrm{~cm}^{2}(n=143)$, 3 Q353 allele carriers and visceral AT $<130 \mathrm{~cm}^{2}(n=20)$, 4 Q353 carriers and visceral $\mathrm{AT} \geq 130 \mathrm{~cm}^{2}(n=35)$. Numbers above the bars indicate groups that differ significantly
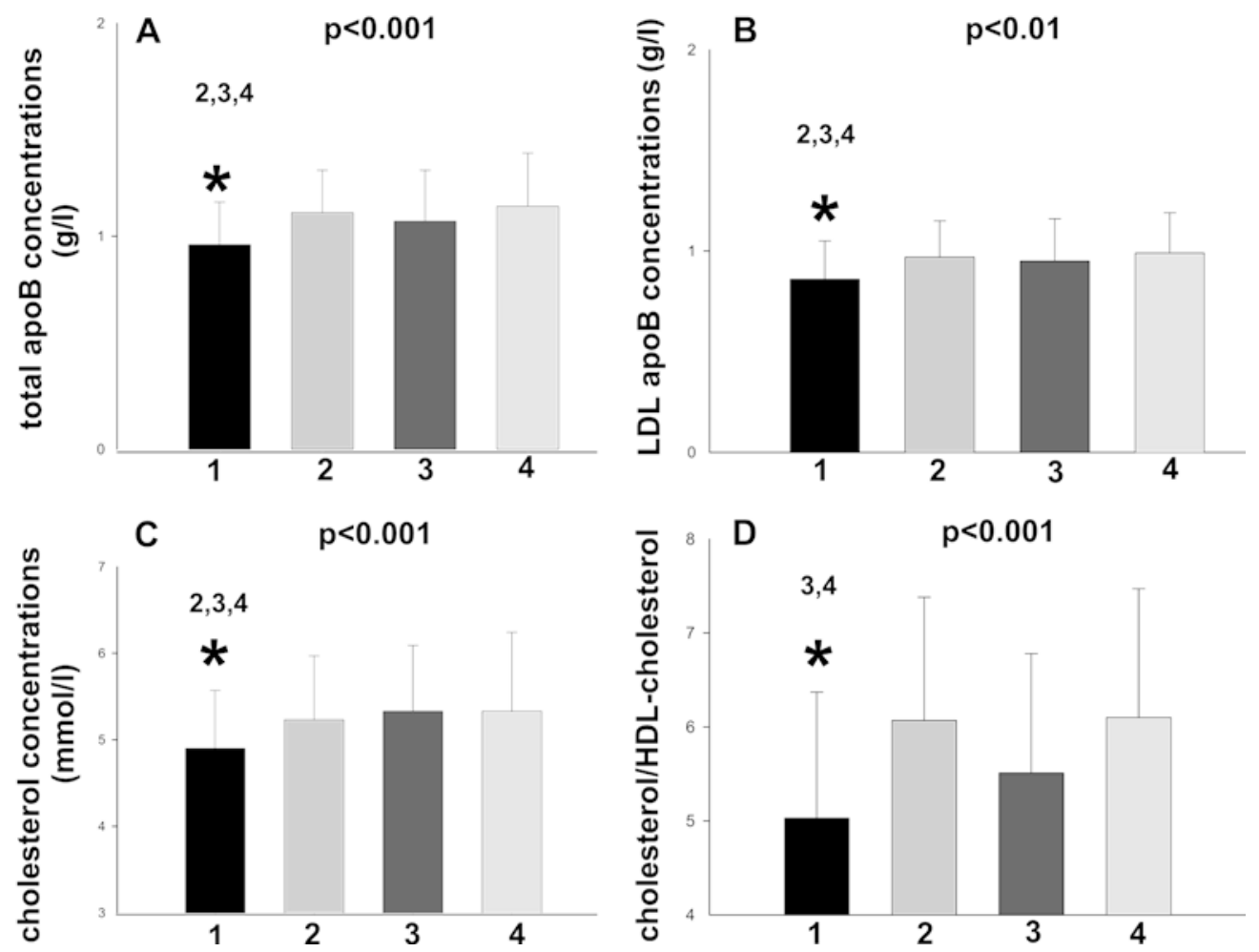

factor VII (Ettelaie et al. 1998). In the present study, the highest concentrations of total-apo B were found in carriers of Q353 allele irrespective of their amount of visceral AT (Fig. 1). Low apo B levels have been associated with a protection against thrombotic complications of cardiovascular diseases (Welty et al. 1997).

However, it is consistently found in diverse populations that Q353 allele was related with a lower risk of cardiovascular disease, and the lowest level and activity of factor VII (Green et al. 1991; Lane et al. 1992; Moor et al. 1995; Mansfield et al. 1996; Humphries et al. 1992; Stengard et al. 2001; Girelli et al. 2000; Wu and Tsongalis 2001). In overweight and obese subjects, metabolic coagulation and fibrinolytic pathological changes are observed and may contribute to the pathogenesis of atherosclerosis vascular disease and to the higher rate of thromboembolic events among these subjects (Avellone et al. 1994).

In the present study, we observed that the relationship between the amount of visceral AT and plasma lipoprotein/lipid levels is altered by the factor VII R353Q missense mutation. Indeed, the amount of visceral AT was positively associated with plasma total-cholesterol, total-cholesterol/HDL-cholesterol ratio and apo B levels in R353/R353 homozygotes only. Moreover, although R353/R353 homozygotes with low visceral AT showed a more favorable lipoprotein/lipid profile, mainly lower total-apo B and LDL-apo B concentrations (Fig. 1A, B), the protective effect of the R353 allele was abolished in the presence of visceral obesity. Carriers of the Q353 allele were characterized by similar apo B levels irrespective of the amount of visceral AT. Similar results were observed for total-cholesterol concentrations and
total-cholesterol/HDL-cholesterol ratio (Fig. 1C, D). It seems that factor VII R353Q polymorphism may have an impact on the development of cardiovascular diseases beyond its traditional role in the coagulation process and that the presence of visceral obesity may modulate the association between lipid profile and genotype.

However, whether a direct link exists between factor VII and apo B levels remains an unanswered question. Vaisanen and co-workers proposed a direct relationship between apo B levels and factor VII activity in Caucasian middle-aged men as they observed using multivariate analyses that apo B, dietary fat and apo AII explained $35.3 \%$ of the variance in factor VII activity (Vaisanen et al. 1995). Carvel de Sousa and co-workers observed that after a standardized test meal, factor VII activity and concentrations, as well as apo B levels, increase in patients who exhibit abnormal triglyceride levels (Carvel de Sousa et al. 1989). In addition, factor VII was proposed to be activated by factor XIIa induced by free fatty acids resulting from the lipolysis of triglyceride-rich lipoproteins in postprandial state (Silveira et al. 1994). The mechanisms by which dietary fats or serum triglycerides stimulate increased hepatic synthesis of vitamin K-dependent clotting factors or prolong their survival in the circulation are unknown. Plasma free TF inhibitor may constitute another pathway because it was found to be correlated with total-cholesterol, apo B and the total amount of factor VII in healthy middle aged men (Hansen et al. 2001). Moreover, because the binding of apo $\mathrm{B}$ to $\mathrm{TF}$ inhibits the procoagulant activity of $\mathrm{TF}$, apo B acts indirectly on factor VII (Ettelaie et al. 1998). The exact mechanism by which factor VII may affect plasma apo B levels remains to be elucidated. 
In summary, the factor VII R353Q polymorphism, or another polymorphism in linkage disequilibrium with this genetic variant is associated with plasma apo B levels. Furthermore, the presence of visceral obesity may modulate the magnitude of this association. Thus, depending upon the factor VII R353Q genotype, visceral obesity may play a trivial or an important role in the etiology of the atherogenic dyslipidemia in men. Further studies will be necessary to confirm this association and the mechanisms involved.

Acknowledgements We are indebted to the subjects involved in this study. Marie-Claude Vohl is recipient of a scholarship from the Fonds de la Recherche en Santé du Québec (FRSQ). Jean Bergeron is a clinical scholar from the FRSQ. Jean-Pierre Després is chair professor of human nutrition, lipidology and prevention of cardiovascular disease supported by Pfizer Canada and Provigo. Part of this work was supported by the Canadian Institutes for Health Research (operating grant: MOP 44074) and the Heart and Stroke Foundation of Canada.

\section{References}

Avellone G, Di Garbo V, Cordova R, Cucinella G, De Simone R, Raneli G, Bompiani G (1994) Evaluation of cardiovascular risk factors in overweight and obese subjects. Int Angiol 13:2529

Bavenholm P, Proudler A, Silveira A, Crook D, Blomback M, de Faire U, Hamsten A (1995) Relationships of insulin and intact and split proinsulin to haemostatic function in young men with and without coronary artery disease. Thromb Haemost 73:568-575

Carvalho de Sousa JC, Bruckert E, Giral P, Soria C, Chapman J, Truffert J, Dairou F, De Gennes JL, Caen JP (1989) Coagulation factor VII and plasma triglycerides. Decreased catabolism as a possible mechanism of factor VII hyperactivity. Haemostasis 19:125-130

Connelly PW, Poapst M, Davignon J, Lussier-Cacan S, Reeder B, Lessard R, Hegele RA, Csima A (1999) Reference values of plasma apolipoproteins A-I and B, and association with nonlipid risk factors in the populations of two Canadian provinces: Quebec and Saskatchewan. Canadian Heart Health Surveys Research Group. Can J Cardiol 15:409-418

de Maat MP, Green F, de Knijff P, Jespersen J, Kluft C (1997) Factor VII polymorphisms in populations with different risks of cardiovascular disease. Arterioscler Thromb Vasc Biol 17:19181923

de Sousa JC, Soria C, Ayrault-Jarrier M, Pastier D, Bruckert E, Amiral J, Bereziat G, Caen JP (1988) Association between coagulation factors VII and $\mathrm{X}$ with triglyceride rich lipoproteins. J Clin Pathol 41:940-944

Desbuquois B, Aurbach GD (1971) Use of polyethylene glycol to separate free and antibody-bound peptide hormones in radioimmunoassays. J Clin Endocrinol Metab 33:732-738

Després JP (1992) Abdominal obesity and the risk of coronary artery disease, Can J Cardiol 8:561-562

Després JP (1994) Dyslipidaemia and obesity. Baillieres Clin Endocrinol Metab 8:629-660

Després JP, Lamarche B (1993) Effects of diet and physical activity on adiposity and body fat distribution: Implications for the prevention of cardiovascular disease. Nutr Res Rev 6:137-159

Després JP, Nadeau A, Tremblay A, Ferland M, Moorjani S, Lupien P, Thériault G, Pinault S, Bouchard C (1989) Role of deep abdominal fat in the association between regional adipose tissue distribution and glucose tolerance in obese women. Diabetes 38:304-309
Després JP, Moorjani S, Lupien P, Tremblay A, Nadeau A, Bouchard C (1990) Regional distribution of body fat, plasma lipoproteins, and cardiovascular disease. Arteriosclerosis 10:497-511

Després JP, Prud'homme D, Pouliot MC, Tremblay A, Bouchard C (1991) Estimation of deep abdominal adipose-tissue accumulation from simple anthropometric measurements in men. Am J Clin Nutr 54:471-477

Després JP, Lamarche B, Mauriège P, Cantin B, Dagenais GR, Moorjani S, Lupien PJ (1996) Hyperinsulinemia as an independent risk factor for ischemic heart disease. N Engl J Med 334:952-957

Ettelaie C, James NJ, Adam JM, Nicola KP, Wilbourn BR, Bruckdorfer KR (1998) Identification of a domain in apolipoprotein B-100 that inhibits the procoagulant activity of tissue factor. Biochem J 333:433-438

Ferland M, Després JP, Tremblay A, Pinault S, Nadeau A, Moorjani S, Lupien PJ, Thériault G, Bouchard C (1989) Assessment of adipose tissue distribution by computed axial tomography in obese women: association with body density and anthropometric measurements. Br J Nutr 61:139-148

Fuster V, Badimon L, Badimon JJ, Chesebro JH (1992) The pathogenesis of coronary artery disease and the acute coronary syndromes (1). N Engl J Med 326:242-250

Girelli D, Russo C, Ferraresi P, Olivieri O, Pinotti M, Friso S, Manzato F, Mazzucco A, Bernardi F, Corrocher R (2000) Polymorphisms in the factor VII gene and the risk of myocardial infarction in patients with coronary artery disease. $\mathrm{N}$ Engl J Med 343:774-780

Green F, Kelleher C, Wilkes H, Temple A, Meade T, Humphries S (1991) A common genetic polymorphism associated with lower coagulation factor VII levels in healthy individuals. Arterioscler Thromb 11:540-546

Hansen JB, Grimsgaard S, Huseby N, Sandset PM, Bonaa KH (2001) Serum lipids and regulation of tissue factor-induced coagulation in middle-aged men. Thromb Res 102:3-13

Heinrich J, Balleisen L, Schulte H, Assmann G, van de Loo J (1994) Fibrinogen and factor VII in the prediction of coronary risk. Results from the PROCAM study in healthy men. Arterioscler Thromb 14:54-59

Humphries SE, Green FR, Temple A, Dawson S, Henney A, Kelleher CH, Wilkes H, Meade TW, Wiman B, Hamsten A (1992) Genetic factors determining thrombosis and fibrinolysis. Ann Epidemiol 2: 371-385

Hunault M, Arbini AA, Lopaciuk S, Carew JA, Bauer KA (1997) The Arg353Gln polymorphism reduces the level of coagulation factor VII. In vivo and in vitro studies. Arterioscler Thromb Vasc Biol 17:2825-2829

Kjalke M, Silveira A, Hamsten A, Hedner U, Ezban M (2000) Plasma lipoproteins enhance tissue factor-independent factor VII activation. Arterioscler Thromb Vasc Biol 20:18351841

Lamarche B, Lemieux I, Despres JP (1999) The small, dense LDL phenotype and the risk of coronary heart disease: epidemiology, patho-physiology and therapeutic aspects. Diabetes Metab 25:199-211

Lane A, Cruickshank JK, Mitchell J, Henderson A, Humphries S, Green F (1992) Genetic and environmental determinants of factor VII coagulant activity in ethnic groups at differing risk of coronary heart disease. Atherosclerosis 94:43-50

Laurell CB (1966) Quantitative estimation of proteins by electrophoresis in agarose gel containing antibodies. Anal Biochem 15:42

Mansfield MW, Heywood DM, Grant PJ (1996) Circulating levels of factor VII, fibrinogen, von Willebrand factor and features of insulin resistance in first-degree relatives of patients with NIDDM. Circulation 94: 2171-2176

Meade TW, Mellows S, Brozovic M, Miller GJ, Chakrabarti RR, North WR, Haines AP, Stirling Y, Imeson JD, Thompson SG (1986) Haemostatic function and ischaemic heart disease: principal results of the Northwick Park Heart Study. Lancet $2: 533-537$ 
Miller GJ, Bauer KA, Barzegar S, Cooper JA, Rosenberg RD (1996) Increased activation of the haemostatic system in men at high risk of fatal coronary heart disease. Thromb Haemost 75:767-771

Moor E, Silveira A, van't Hooft F, Suontaka AM, Eriksson P, Blomback M, Hamsten A (1995) Coagulation factor VII mass and activity in young men with myocardial infarction at a young age. Role of plasma lipoproteins and factor VII genotype Arterioscler Thromb Vasc Biol 15:655-664

Moorjani S, Dupont A, Labrie F, Lupien PJ, Brun D, Gagné C, Giguère M, Bélanger A (1987) Increase in plasma high-density lipoprotein concentration following complete androgen blockage in men with prostatic carcinoma. Metabolism 36:244-250

Pankow JS, Folsom AR, Shahar E, Tsai MY, Jeffery RW, Wing RR (1998) Weight-loss induced changes in plasma factor VII coagulant activity and relation to the factor VII Arg/Gln353 polymorphism in moderately obese adults. Thromb Haemost 79:784-789

Peiris AN, Sothmann MS, Hoffmann RG, Hennes MI, Wilson CR, Gustafson AB, Kissebah AH (1989) Adiposity, fat distribution, and cardiovascular risk. Ann Intern Med 110:867-872

Pouliot MC, Després JP, Nadeau A, Moorjani S, Prud'homme D, Lupien PJ, Tremblay A, Bouchard C (1992) Visceral obesity in men. Associations with glucose tolerance, plasma insulin, and lipoprotein levels. Diabetes 41:826-834

Rao LV, Rapaport SI (1988) Activation of factor VII bound to tissue factor: a key early step in the tissue factor pathway of blood coagulation. Proc Natl Acad Sci USA 85:6687-6691

Richterich R, Dauwalder H (1971) Zur bestimmung der plasmaglukosekonzentration mit der hexokinase-glucose-6-phosphat-dehydrogenase-method. Schweiz Med Wochenschr 101:615-618

Saha N, Liu Y, Heng CK, Hong S, Low PS, Tay JS (1994) Association of factor VII genotype with plasma factor VII activity and antigen levels in healthy Indian adults and interaction with triglycerides. Arterioscler Thromb 14:1923-1927

Silveira A, Karpe F, Blomback M, Steiner G, Walldius G, Hamsten A (1994) Activation of coagulation factor VII during alimentary lipemia. Arterioscler Thromb 14:60-69

Stengard JH, Salomaa V, Rasi V, Vahtera E, Ehnholm C, Krusius T, Perola M, Vartiainen E (2001) Utility of the Arg/Gln polymorphism of the factor VII (FVII) gene, serum lipid levels and body mass index in the prediction of the FVII:C and FVII:Ag in North Karelia; a cross-sectional and prospective study. Blood Coagul Fibrinolysis 12:445-452

Vaisanen S, Rankinen T, Penttila I, Rauramaa R (1995) Factor VII coagulant activity in relation to serum lipoproteins and dietary fat in middle-aged men. Thromb Haemost 73:435-438

Vambergue A, Rugeri L, Gaveriaux V, Devos P, Martin A, Fermon C, Fontaine B, Jude B (2001) Factor VII, tissue factor pathway inhibitor, and monocyte tissue factor in diabetes mellitus: influence of type of diabetes, obesity index, and age. Thromb Res 101:367-375

Van der kooy K, Seidell JC (1993) Techniques for the measurement of visceral fat: a practical guide. Int J Obes Relat Metab Disord 17:187-196

Vergnani L, Zuliani G, Ricci F, Manzoli N, Carantoni M, Volpato S, Fellin R (1998) Fibrinolytic and coagulation factors in very old subjects: association with lipoprotein profile and anthropometric variables. J Gerontol A Biol Sci Med Sci 53:M8-13

Welty FK, Mittleman MA, Wilson PW, Sutherland PA, Matheney TH, Lipinska I, Muller JE, Levy D, Tofler GH (1997) Hypobetalipoproteinemia is associated with low levels of hemostatic risk factors in the Framingham offspring population. Circulation 95:825-830

Wu AH, Tsongalis GJ (2001) Correlation of polymorphisms to coagulation and biochemical risk factors for cardiovascular diseases. Am J Cardiol 87:1361-1366 